\title{
A PMU based special protection scheme: a case study of Taiwan power system
}

\author{
Yi-Jen Wang ${ }^{\mathrm{a}}$, Chih-Wen Liu ${ }^{\mathrm{a}, *}$, Yuin-Hong Liu ${ }^{\mathrm{b}}$ \\ ${ }^{a}$ Department of Electrical Engineering, National Taiwan University, BL628, Taipei 106, Taiwan \\ ${ }^{\mathrm{b}}$ System Operation Department, Taiwan Power Company, Taipei, Taiwan \\ Received 4 December 2001; revised 5 August 2004; accepted 24 September 2004
}

\begin{abstract}
This paper proposes a special protection scheme to prevent power system blackout due to a sequence of relay trip events based on phasor measurement units (PMUs). In a control center, we use PMU's to monitor the generators and the major EHV transmission lines of a power system, and apply an instability prediction algorithm for initiating a special protection schemes (SPS) to avoid a sequence of relay trip events whenever necessary. When a fault happens, we group the generators swinging coherently and reduce the system to One-Machine-InfiniteBus (OMIB) system. The remedial control actions consist of load shedding and generation tripping. The strategy for determining the amount of remedial control actions is a proposed relay setting limited equal-area criterion for OMIB. A case study of Taiwan power system assumed to be equipped with proposed special protection scheme is conducted. Encouraging results are obtained.
\end{abstract}

(C) 2004 Elsevier Ltd. All rights reserved.

Keywords: PMU; Blackout; Special protection schemes (SPS); Remedial action schemes (RAS); Transient stability

\section{Introduction}

Electric power systems in Taiwan are undergoing significant change. Due to ever-increasing environmental and economical pressures, it becomes extremely difficult to construct new transmission or generation facilities. As a result of the limited power supply and steady growth of load demand, Taiwan Power System (Taipower system) has a severe area generation-load imbalance and a heavy power transfer between northern area and southern area over two $345 \mathrm{kV}$ transmission line. Therefore the operating point is pushed closer to the stability boundary and the system is increasing susceptible to transient instability condition following a severe disturbance such as three-phases short circuits of EHV transmission lines. In fact, on July 29, 1999, Taipower system experienced an outage (call 729 event) due to a collapse of a $345 \mathrm{kV}$ transmission tower, which results in about $80 \%$ power interruption of total energy lasting

\footnotetext{
* Corresponding author. Tel.: +886233663 616; fax: +886223638 247.

E-mail address: cwliu@cc.ee.ntu.edu.tw (C.-W. Liu).
}

several hours [1]. Thus, the issue of maneuvering a system to a more secure operating condition by on-line stability monitoring and control becomes a critical task for Taipower system.

Traditionally, special protection schemes (SPS) [2] (also called remedial action schemes or RAS) are designed to detect abnormal system condition, typically contingencyrelated, and initiate pre-planned, remedial control action such as generation tripping, load shedding and system separation, etc. to mitigate the consequence of the abnormal condition and provide acceptable system performance. SPS can provide remedial control actions and are often used to increase the transfer capability of the transmission system. Compared with constructing new transmission facilities, SPS can be installed relatively quickly and inexpensively. However, conventional SPS may result in risk to system reliability by failure to operate when required and nuisance tripping when unintended. To increase meaningful decisions of SPS, the precise knowledge of the current state of the power system must be acquired in real-time. Fortunately, the recent advent of synchronized Phasor measurement unit (PMU) using the global positioning 
system (GPS) of satellites for synchronization has made possible a state estimate that is a true snapshot of the power system [3]. Furthermore, the state could be renewed in tens of millisecond; thus, it is possible to track the system dynamic phenomena in real-time and make much more meaningful decision for SPS.

In this paper, we propose a PMU based SPS against transient instabilities caused by EHV transmission line failures. Specifically, the proposed SPS is applied to Taipower systems. Simulation results are shown to demonstrate the effectiveness of the proposed method in the last section.

\section{Configuration and algorithms}

\subsection{Configuration}

Due to the most power system load centers and generators are not in the same area, so EHV tie lines are needed to transfer large power between areas. If one or more than one tie line are tripped due to faults, the power that transfers in the faulted line before faults may transfer by the other tie lines between the areas. If the transfer power is very large, it may cause the other tie lines overloaded. This will cause a successive relay trips resulting in the system blackout. We propose a method in real-time to predict the system stability, and determine the amount of remedial control actions to stabilize the system whenever necessary.

Fig. 1 shows the PMU based special protection scheme. In a control center, we use PMU's to monitor the generators and the major EHV transmission lines of a power system, and apply an instability prediction algorithm for initiating a SPS to avoid a sequence of relay trip events whenever necessary. When a fault happens, we group the generators swinging coherently and reduce the system to OneMachine-Infinite-Bus (OMIB) system. Then using realtime phasor measurements to estimate the parameters of OMIB system. The remedial control action consists of load shedding and generation tripping. The algorithm for determining the timing and amount of the remedial control

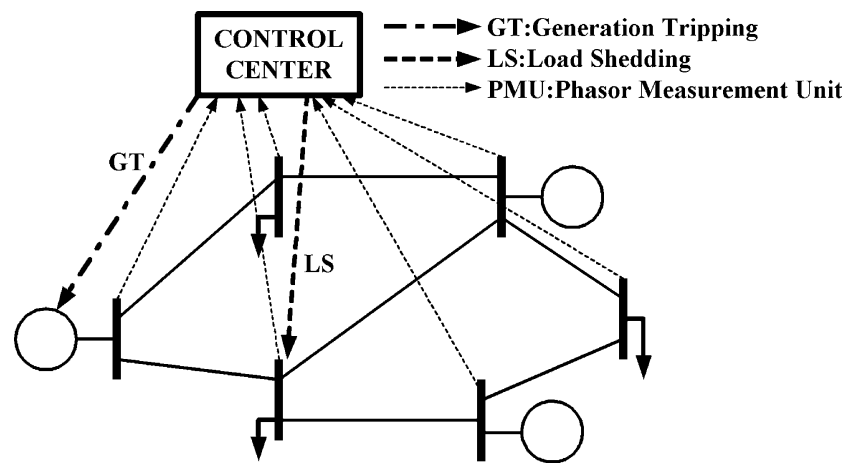

Fig. 1. The PMU based special protection scheme.

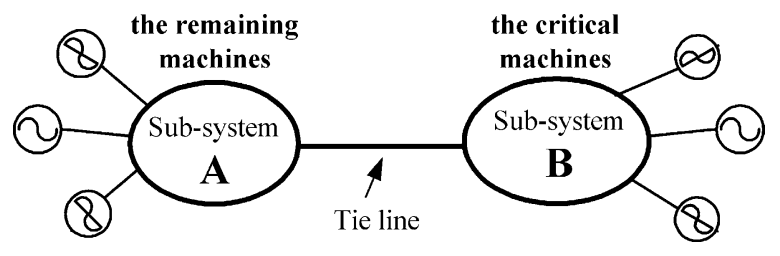

Fig. 2. Two-machine equivalent system.

action is a proposed relay setting limited equal-area criterion. The following steps are the proposed SPS.

1. Group generators swinging coherently and reduce the system to an OMIB system (This step is conducted offline based on large simulation results. For a longitudinal system, like Taipower system, it is not hard to group the generators after faults).

2. Estimate the parameters of an OMIB system using realtime phasor measurements.

3. Determine the timing and amount of the remedial control action by relay setting limited equal-area criterion (EAC) method.

\subsection{Real-time parameter estimation}

In a power system consisting of two synchronous machines and a tie line over which synchronizing power can flow, the problem of instability detection can be solved in real-time [4]. A modified equal-area criterion (called relay setting limited EAC method) is applicable in this case, and if the machine rotor angles and speeds can be measured in real-time a prediction algorithm can be developed for the detection of instability. When ac power imported over relatively long distances for example Taipower system, so that both the sending system and receiving system consist of groups of coherent generators, one of the modes of oscillations of such a power system is that of a two-machine system.

In the two-machine equivalent of a power system, it is assumed that for an assigned fault, the power system is decomposed into two subsets: (1) the critical cluster of machine(s) B, and (2) the remaining machines A (Fig. 2). The former is responsible for system separation when it arises. Then the two subset are transformed into two equivalent machines, modeled within their corresponding frame of partial center of angle (COA), and with the assumption of strong coherency of machines in each cluster, the two-machine equivalent system is further reduced to an OMIB system (Fig. 3). The dynamics of OMIB system is

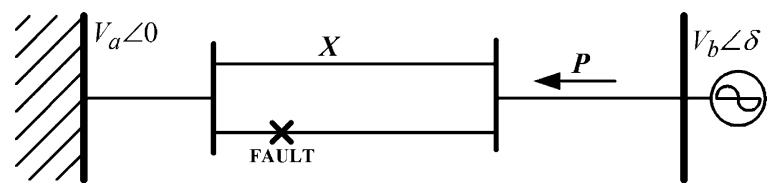

Fig. 3. One-machine-Infinite-bus (OMIB) system. 
governed by the following swing equation

$\ddot{\delta}=P+B \cos (\delta)+C \sin (\delta)$

One of our task is to estimate the parameters of (1), where $\delta$ may represent the rotor angle difference between two machines, one in each group, or else the angle difference between two partial COA's of the two groups. Since the estimation relies on measuring $\delta$, we require any generator angle appearing in the partial COA expressions to be measurable. Let $\delta(m \Delta t), m=0, \ldots, N$, be the measurements of $\delta$, where $\Delta t$ is the sampling interval. We assume, without loss of generality, that the first sample occurs at time $t=0$ for the sake of notation. The second derivative $\ddot{\delta}(t)$ can be approximated by

$$
\begin{gathered}
\ddot{\delta}(m \Delta t) \approx \frac{\delta((m+1) \Delta t)-2 \delta(m \Delta t)+\delta((m-1) \Delta t)}{(\Delta t)^{2}} \\
m=1,2, \ldots, N-1
\end{gathered}
$$

We seek to estimate parameters $P, B$ and $C$ such that the measurements $\delta(m \Delta t)$ fit the model in an optimal way. Consider the error function

$$
e(t)=\ddot{\delta}(t)-P-B \cos \delta(t)-C \sin \delta(t)
$$

where $e(t)$ can be thought of as a function of the parameters $P, B$ and $C$. A good estimation of $P, B$ and $C$, based on the samples $\delta(m \Delta t)$; should make the error function $e(m \Delta t)$ small. One way to achieve this is by least squares, i.e. by minimizing

$$
P, B, C \sum_{m=1}^{\min } e^{2}(m \Delta t)
$$

The summation ranges from 1 to $N-1$, because $\ddot{\delta}(0)$ and $\ddot{\delta}(N \Delta t)$ are not available.

Let

$A=\left[\begin{array}{ccc}1 & \cos \delta(\Delta t) & \sin \delta(\Delta t) \\ \vdots & \vdots & \vdots \\ 1 & \cos \delta((N-1) \Delta t) & \sin \delta((N-1) \Delta t)\end{array}\right]$,

$b=\left[\begin{array}{c}\ddot{\delta}(\Delta t) \\ \vdots \\ \ddot{\delta}((N-1) \Delta t)\end{array}\right]$

Then, the least square estimate of parameters $P, B$, and $C$ is

$$
\left[\begin{array}{l}
P \\
B \\
C
\end{array}\right]=\left(A^{T} A\right)^{-1} A^{T} b
$$

Remark 1. We have used the phrase 'generator rotor angles' interchangeablely with 'phasor measurements'. What we are intending is that when you have a phasor measurement unit located on the EHV or HV bus of a generating plant, that you will have a suitably detailed model of the generator for simulation purposes, but also have a classical generator model consisting of a voltage source behind a transient reactance. The $i$ th generator internal voltage in the classical model is easily computed from the terminal voltage and current phasor measurements

$\bar{E}_{i}=\bar{V}_{t, i}+\bar{I}_{t, i} \times j X_{d, i}^{\prime}$

where $\bar{E}_{i}=\left|\bar{E}_{i}\right| \angle \delta_{i}$ is the $i$ th generator interal voltage phasor.

$\bar{V}_{t, i}=\left|\bar{V}_{t, i}\right| \angle \theta_{V, i}, \bar{I}_{t, i}=\left|\bar{I}_{t, i}\right| \angle \theta_{I, i}$ are the $i$ th generator terminal voltage and current measured phasors by PMU.

$X_{d, i}^{\prime}$ is the $i$ th generator transient reactance.

Remark 2. Since we want to detect transient instability as early as possible, the window should be chosen as short as possible from this point. On the other hand, we need enough measurements to identify the system parameters. Therefore, there is a trade-off between these things. A reasonable choice is that the dimension of matrix $A$, which equals to $N-1$, is about twice than the number of unknow parameters.

Remark 3. Depending on the swings to be predicted, local devices compute generator rotor angles from terminal bus angles, then transimit these angle to central center where transient stability prediction and the amount of remedial control action are determined. Although synchronized phasor measurements are performed constantly at a high sampling rate, say, 12 times per cycle [3], we should consider the time for transmission of angle data. It is reasonable to assume that we can obtain all synchronized data of interest at a rate of once every two cycles.

\subsection{Relay setting limited equal-area criteria}

In an OMIB system if a fault or disturbance causes the machine to start swinging with respect to an infinite bus, EAC can determine the stability of the system under

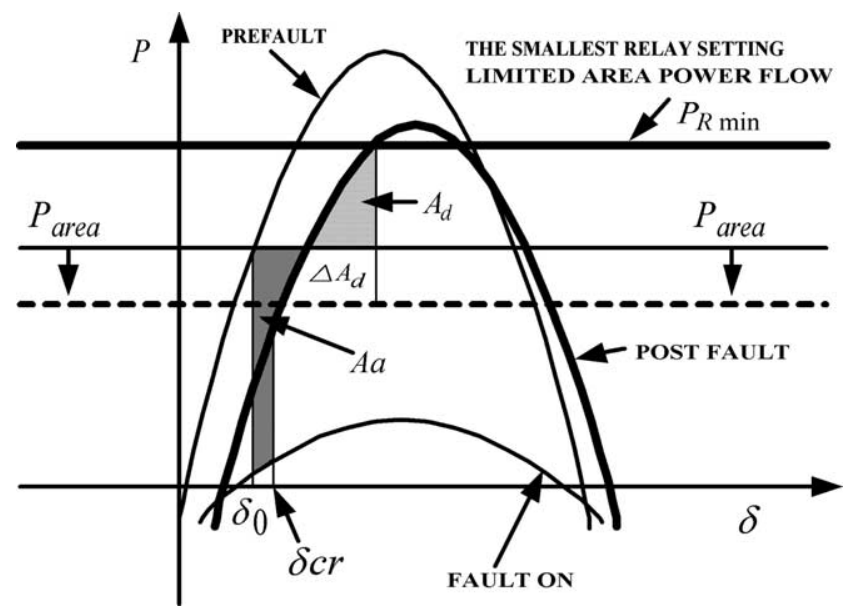

Fig. 4. The concept of relay setting limited EAC method. 


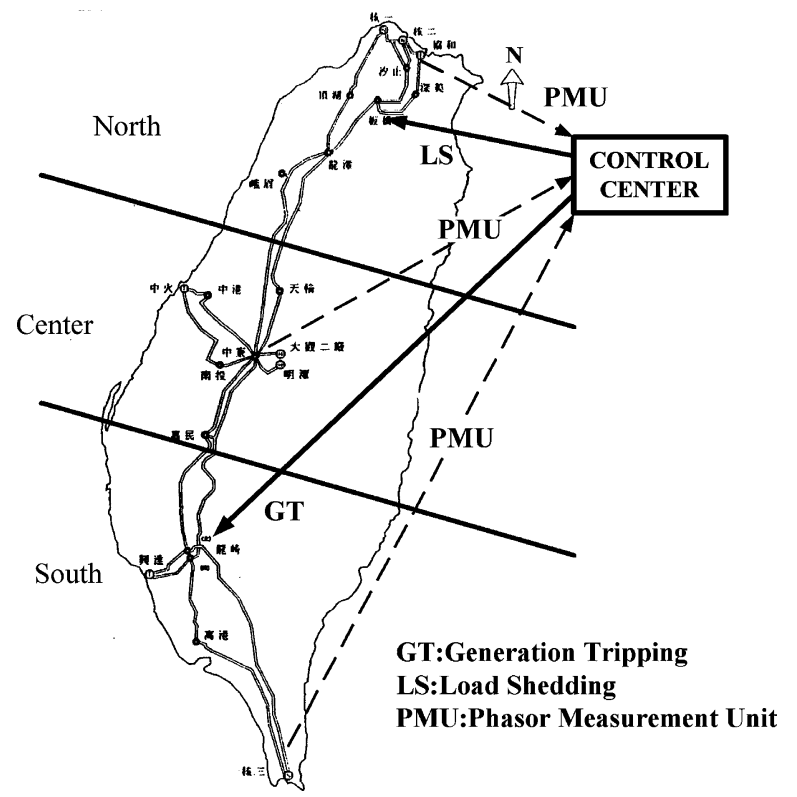

Fig. 5. Structure of the Taiwan $345 \mathrm{kV}$ system including the proposed scheme.

transient conditions without solving the swing equation Power angle curves are used to analyze the physical conditions before, during and after a fault. We obtain the postfault system power angle curve by using estimated system parameters $P, B$, and $C$. The EAC method can decide the stability of the systems. Our method is to prevent the EHV tie lines far from cascade tripping, so we use the smallest relay setting limited area power flow, to modify the EAC methods. We transform the tie line relay setting to the equivalent relay setting limited area power flow, and choose the smallest relay setting limited area power flow to determine the stability. For example, the current setting of the $i$ th tie line relay can be transformed to an relay setting power, $P_{\mathrm{set}, i}$, by the equation:

$P_{\text {set }, i}=\sqrt{3} \times($ rated line voltage $) \times($ current setting $)$

We transform the relay setting power to the equivalent relay setting limited area power flow by the following equation

$P_{\mathrm{R}, i}=P_{\text {area }}+\frac{P_{\text {area }}}{P_{\text {line }, i}} \times\left(P_{\text {set }, i}-P_{\text {line }, i}\right)$

$P_{\mathrm{Rmin}}=\operatorname{Min}\left(P_{R, i}\right), \quad i=1,2, \ldots$, all tie-lines

Table 1

Summary for Taipower system facility

\begin{tabular}{lcc}
\hline & Peak load & Off-peak load \\
\hline No. of buses & 467 & 467 \\
No. of plants & 84 & 84 \\
No. of machines & 80 & 52 \\
No. of loads & 166 & 166 \\
No. of branches & 716 & 716 \\
No. of transformers & 395 & 395 \\
\hline
\end{tabular}

Table 2

Area generations and load (MW)

\begin{tabular}{lcll}
\hline Peak load & North & Center & South \\
\hline Generation & 6310 & 8941 & 9317 \\
Load + loss & 11,314 & 7487 & 5767 \\
Surplus power & -5004 & 1454 & 3550 \\
Off-peak load & North & Center & South \\
\hline Generation & 3838 & 5666 & 7321 \\
Load + loss & 6496 & $4178(+2500)$ & 3651 \\
Surplus power & -2658 & -1012 & 3670
\end{tabular}

The number in the parenthesis is the pump-storage pump power.

Table 3

Transfer power between areas (MW)

\begin{tabular}{lll}
\hline & Center to north & South to center \\
\hline Peak load & 5004 & 3550 \\
Off-peak load & 2658 & 3670 \\
\hline
\end{tabular}

where

$P_{\mathrm{Rmin}}$ is the smallest relay setting limited area power flow.

$P_{\mathrm{R}, i} \quad$ is the $i$ th tie line equivalent relay setting limited area power flow due to the $i$ th tie line relay setting.

$P_{\text {area }}$ is the measured area power flow between the areas.

$P_{\text {line }, i}$ is the measured power on the $i$ th tie line.

$P_{\text {set }, i}$ is the $i$ th tie line relay setting power.

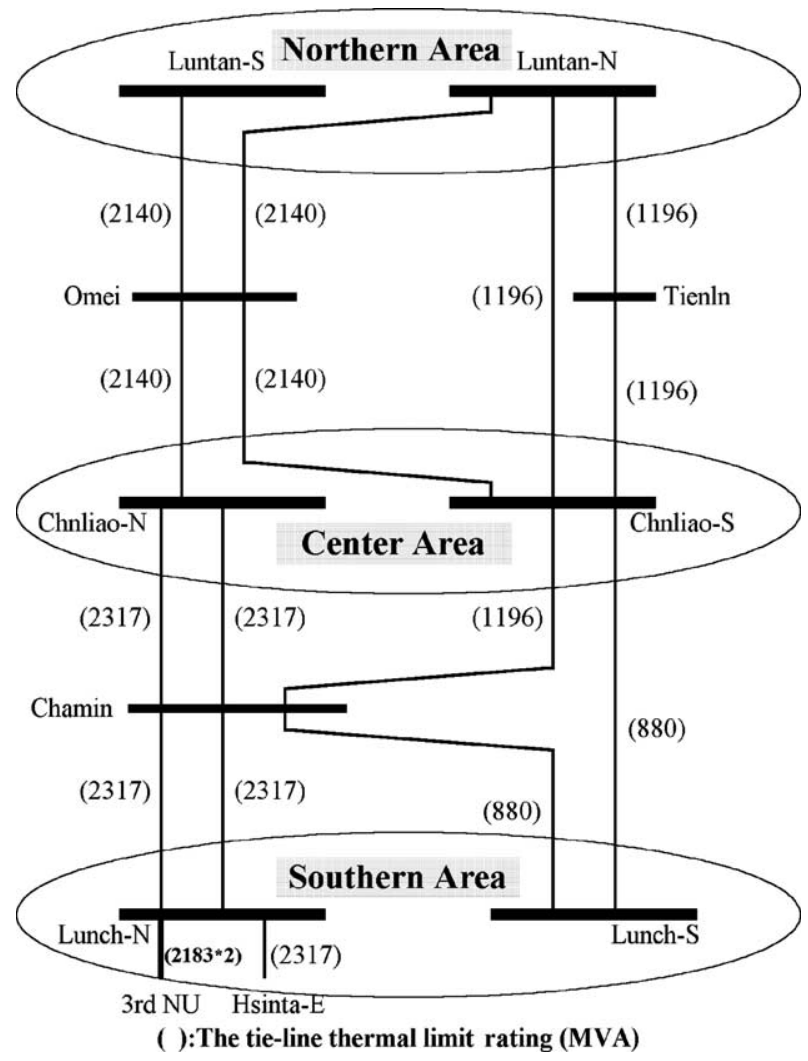

Fig. 6. One-line diagram of main $345 \mathrm{kV}$ transmission systems. 
Table 4

Summaries of models

\begin{tabular}{ll}
\hline Machine & Model name (Number) \\
\hline Generators & GENROU(62), GENSAL(22) \\
Stabilizers & STAB1(1), IEEEST(5), PTIST1(8) \\
Exciter systems & IEEET1(30), IEEET3(13), IEEET5(1), SCRX(23), \\
& IEEX2A(2), EXAC1(2), EXAC3(12) \\
Governors & GAST(20), HYGOV(21), IEESGO(41) \\
\hline
\end{tabular}

The principle of the relay setting limited EAC is described as follows. In Fig. 4 , the computed $P_{\mathrm{Rmin}}$ is the smallest relay setting limited area power flow, and $P_{\text {area }}$ is the measured area power flow. If the accelerating area $A_{\mathrm{a}}$ is greater than the decelerating area $A_{\mathrm{d}}$, shown in Fig. 4 , then the system swing will enter other tie line relay protective zones and may cause a cascade trips to deteriorate the stability condition. By adjusting $P_{\text {area }}$ to the dot line in Fig. 4, which means the load shedding and generation tripping is activated simultaneously, such that $A_{\mathrm{a}} \leq A_{\mathrm{d}}+\Delta A_{\mathrm{d}}$, then the system swing will not cause a second trip and the system will be stabilized. The amount of remedial actions is the value of the reduced $P_{\text {area }}$. The load shedding sequence is predetermined by the contract with the customers and the load survey. The generation tripping sequence is in the order of accelerating kinetic energy except base generators, that is, the generator with maximum accelerating kinetic energy will be tripped first.

\section{Case study}

\subsection{System description}

The system under study is the Taipower system in the year 1999. The Taipower system structure is a longitudinal one with three major areas on the island, namely, North, Center, and South, connected together by a number of $345 \mathrm{kV}$ transmission lines. Its structure is illustrated in Fig. 5.
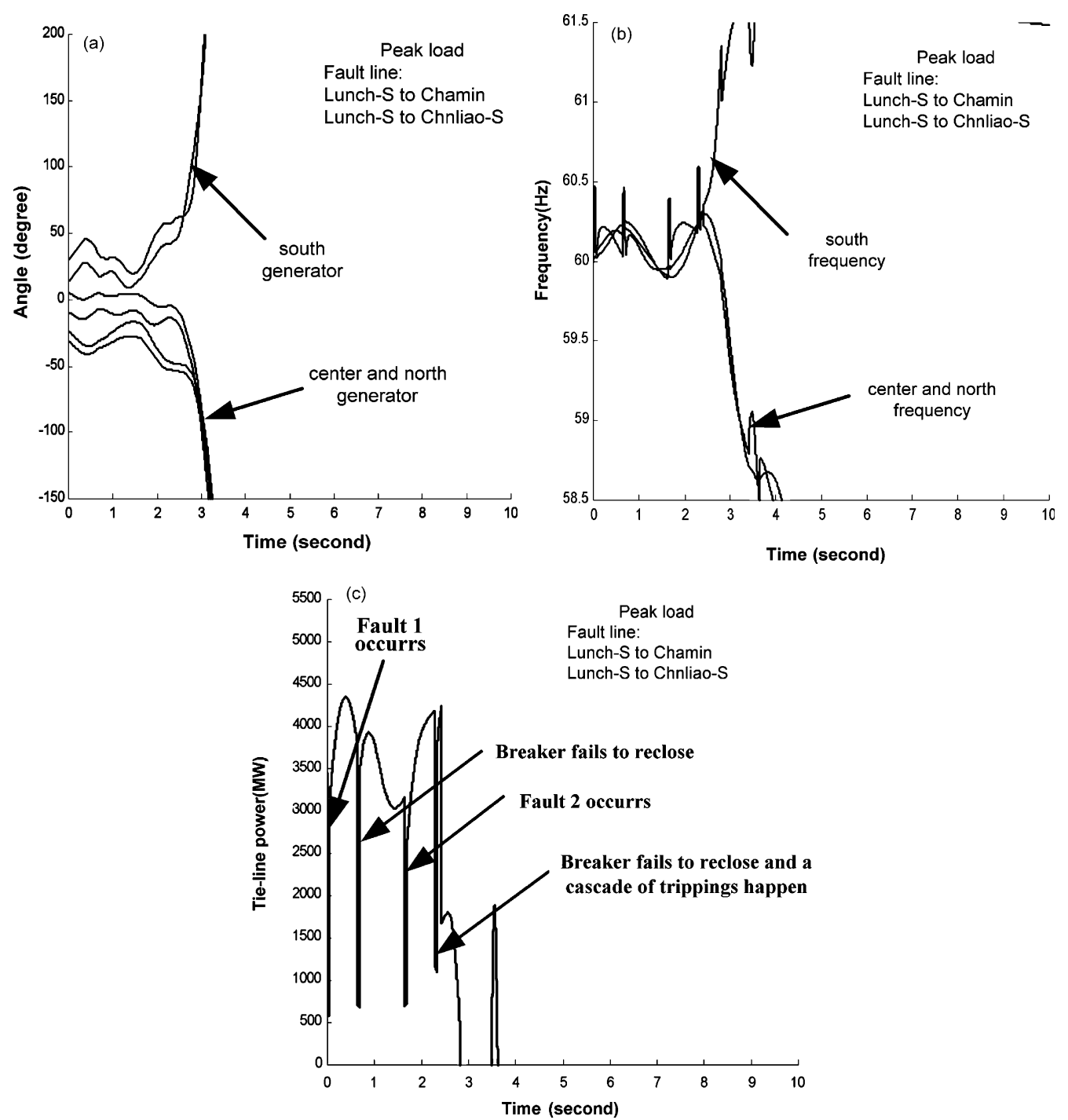

Fig. 7. Simulation results of 729-event: (a) generator angle, (b) system frequency, (c) areas transfer power 
Since major load centers are located in the north and most generating plants are in the central and southern areas, significant power transfers from central area and southern area to the northern area have been experienced in the past few years.

Table 1 summarizes the Taipower system. System planners at Taiwan Power Company establish two representative power flows, one for peak load and the other for off-peak load. Table 2 summarizes area generation and load for the peak and off-peak load patterns under study. It is observed from Table 2 that the deficit power in the northern area must be supplied from the generators in the central and southern areas through the 345 and $161 \mathrm{kV}$ tie lines between areas. Table 3 shows the transfer power between the areas. Since most of the inter-area power flows are transmitted through $345 \mathrm{kV}$ lines, how to protect these EHV tie lines far from the cascade events will be of major concern in this work.

\subsection{Protective systems}

Fig. 6 depicts an one-line diagram of the main $345 \mathrm{kV}$ transmission systems connecting the North, the Center and the South areas. The surplus power in the central and southern areas is transmitted to the North through two parallel circuits. Every circuit has two parallel three-phase transmission lines, which are built on the same iron tower. For protecting the $345 \mathrm{kV}$ transmission systems we simulate Mho distance relays and overcurrent relays on every $345 \mathrm{kV}$ tie line between areas. The Mho distance relay protective zones are set to be 92,150 and $220 \%$ of line impedance for zones 1, 2 and 3, whose pickup times are 1.5, 10 and 60 cycles, respectively. All opening time of circuit breakers is 1.5 cycles and re-close time is 36 cycles. The operating currents of overcurrent relays are set to be $1.5 \times$ (line thermal rating) and delay time is $0.6 \mathrm{~s}$.

\subsection{Simulation results}

On July 29, 1999, a severe fault occurred on the major $345 \mathrm{kV}$ tie line circuit between the southern area and the center area, which carried more than $1500 \mathrm{MW}$ and caused a successive relay trips resulting in system north and center area blackout (729-event). Almost total $80 \%$ consumers had an interruption lasting several hours in 729-event, and affected more people and extended over a wider geographic area than any previous outages.

To verify the proposed method, simulations are performed using the Power Technologies Incorporated (PTI) PSS/E-24 simulator program on the Taipower system. The automation process was achieved using FORTRAN program, which was written into the PSS/E-24 simulator program by the author. The Taipower system has a total of 467 buses, 80 machines, which were modeled in details including exciter systems, stabilizers, and governors. The system has 166 load buses with nonlinear composite load models. Table 4 summarizes the complete power system models names and numbers. We simulate the 729 events which has two three phase short circuit faults at $t=0$ and $1.632 \mathrm{~s}$ on the same iron tower's circuit between the southern area and the center area. The simulation results are in the Fig. 7. The simulation results agree well with the measurement records of 729-event [1]. From Fig. 7, at $t=0$ the first fault occurs due to the collapse of iron tower and trips the faulted line after three cycles by the Mho distance relay. After 36 cycles later, $t=0.65 \mathrm{~s}$, the breaker recloses and fails because the fault is not cleared. At $t=1.632 \mathrm{~s}$, the fault 2 happens due to the same iron tower collapse and tripps the fault line after three cycles by the Mho distance relay. After 36 cycles later, $t=2.282 \mathrm{~s}$, the breaker recloses and fails because the fault is not cleared. Because the two lines trip due to the iron tower collapse, the other circuits have an overloading condition between southern area and center area and a successive relay trippings occur. A transient instability condition occurs.

Now, we assume that the Taipower system was armed with PMU based SPS. Then 729 event is simulated again. The estimated parameter results of OMIB system using realtime phasor measurements are showed in Fig. 8. The remedial action is taken after the second faults fails. The amount of remedial action is $1332 \mathrm{MW}$. That is, the rejection of southern generators is $1332 \mathrm{MW}$, and the shedding of northern load is $1332 \mathrm{MW}$. The results are shown in Fig. 9.

To further verify the proposed SPS on the Taipower system, we used the Eight cases like 729-event but at different places listed in Table 5. The simulation results are shown in Table 6. Fig. 10 shows the response of

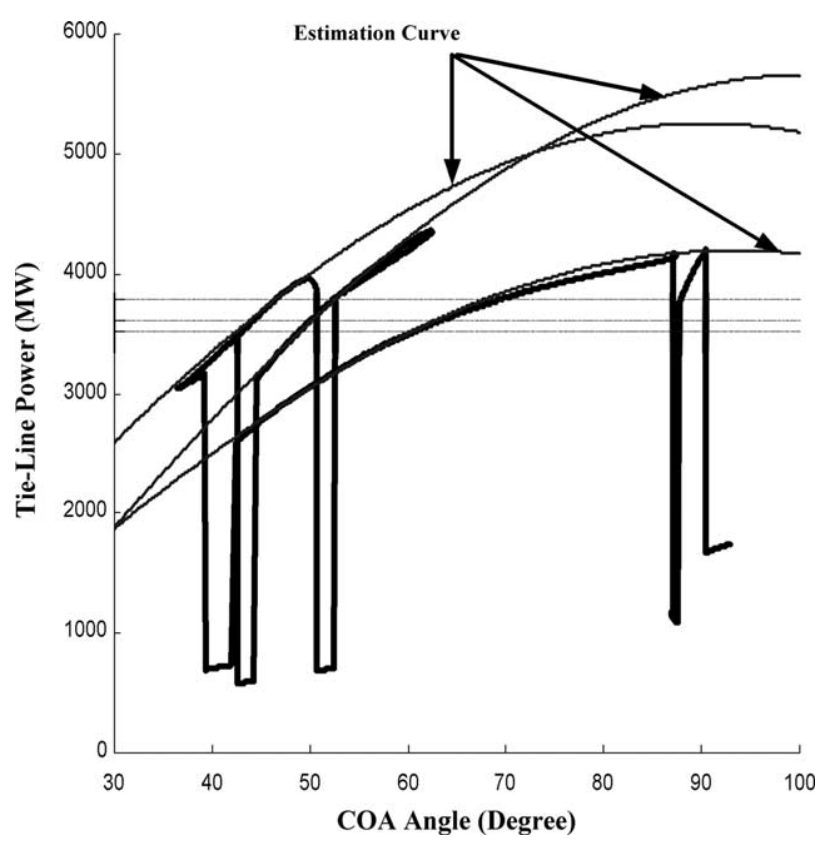

Fig. 8. The estimation curves of OMIB system. 

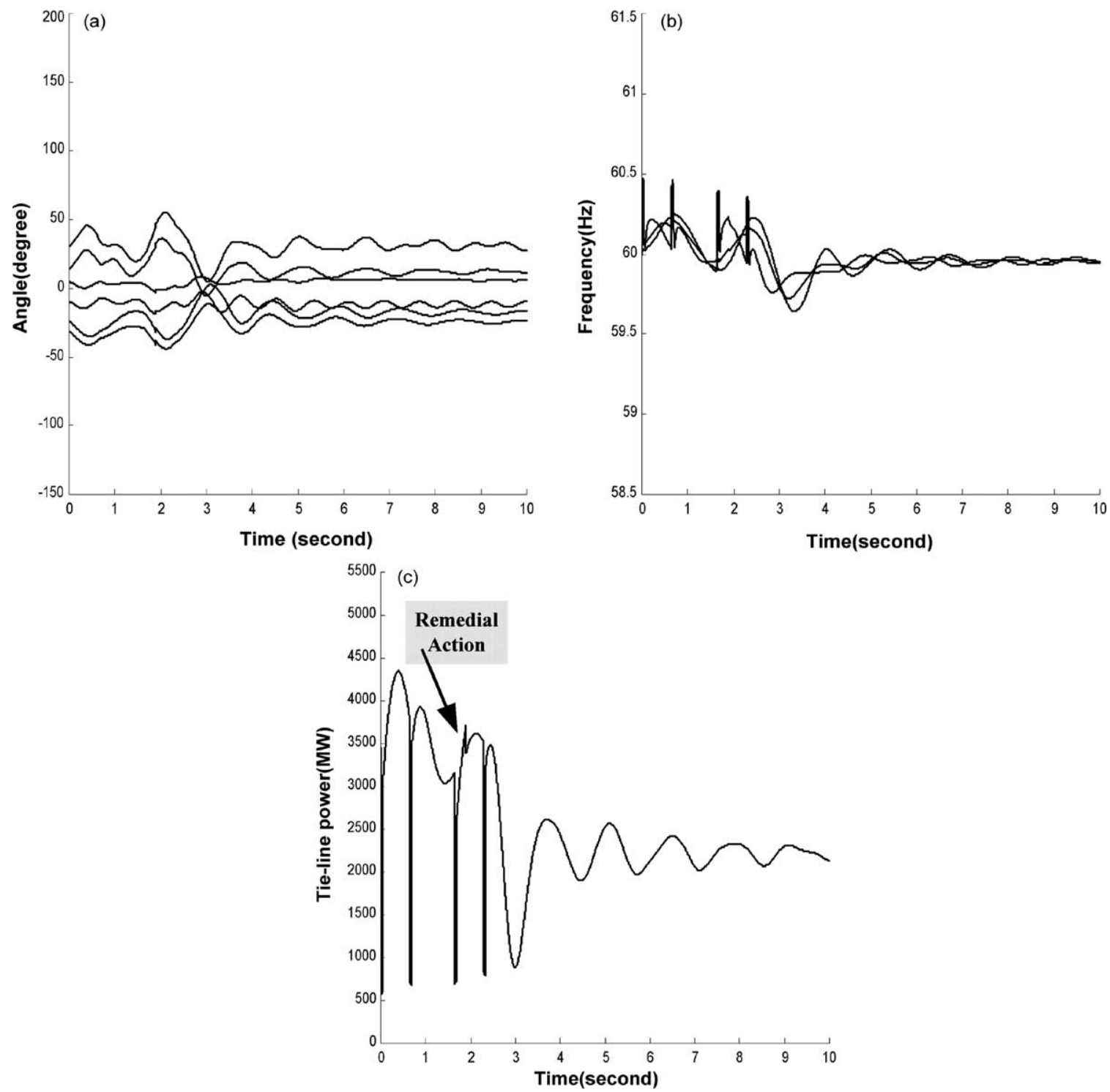

Fig. 9. Simulation results of 729-event with PMU based SPS: (a) generator angle, (b) system frequency, (c) areas transfer power.

Table 5

Summaries of study cases

\begin{tabular}{|c|c|c|}
\hline Case & Load & Description \\
\hline 1 & Peak & $\begin{array}{l}\text { 3PSC between Lunch-S and Chamin at } t=0.0(\mathrm{~s}) \\
\text { 3PSC between Lunch-S and Chnliao-S at } t=1.632(\mathrm{~s})\end{array}$ \\
\hline 2 & Peak & $\begin{array}{l}\text { 3PSC between Lunch- } N \text { and Chamin circuit } 1 \text { at } t=0.0(\mathrm{~s}) \\
\text { 3PSC between Lunch- } N \text { and Chamin circuit } 2 \text { at } t=1.632(\mathrm{~s})\end{array}$ \\
\hline 3 & Peak & $\begin{array}{l}\text { 3PSC between Chnliao- } S \text { and Tienln at } t=0.0(\mathrm{~s}) \\
\text { 3PSC between Chnliao- } S \text { and Luntan- } N \text { at } t=1.632(\mathrm{~s})\end{array}$ \\
\hline 4 & Peak & $\begin{array}{l}\text { 3PSC } \mathrm{t} \text { between Chnliao- } S \text { and Omei at } t=0.0(\mathrm{~s}) \\
\text { 3PSC between Chnliao- } N \text { and Omei at } t=1.632(\mathrm{~s})\end{array}$ \\
\hline 5 & Off- peak & $\begin{array}{l}\text { 3PSC between Lunch- } S \text { and Chamin at } t=0.0(\mathrm{~s}) \\
\text { 3PSC between Lunch-S and Chnliao- } S \text { at } \mathrm{t}=1.632(\mathrm{~s})\end{array}$ \\
\hline 6 & Off-peak & $\begin{array}{l}\text { 3PSC between Lunch- } N \text { and Chamin circuit } 1 \text { at } t=0.0(\mathrm{~s}) \\
\text { 3PSC between Lunch- } N \text { and Chamin circuit 2at } t=1.632(\mathrm{~s})\end{array}$ \\
\hline 7 & Off-peak & $\begin{array}{l}\text { 3PSC between Chnliao-S and Tienln at } t=0.0(\mathrm{~s}) \\
\text { 3PSC between Chnliao- } S \text { and Luntan- } N \text { at } t=1.632(\mathrm{~s})\end{array}$ \\
\hline 8 & Off-peak & $\begin{array}{l}\text { 3PSC between Chnliao-S and Omei at } t=0.0(\mathrm{~s}) \\
\text { 3PSC between Chnliao- } N \text { and Omei at } t=1.632(\mathrm{~s})\end{array}$ \\
\hline
\end{tabular}

3PSC, three phase short circuit fault. 
Table 6

Summaries of simulation results

\begin{tabular}{|c|c|c|c|c|c|}
\hline Condition & Algorithms & Case 1 & Case 2 & Case 3 & Case 4 \\
\hline Peak load & $\begin{array}{l}\text { No action } \\
\text { The proposed SPS }\end{array}$ & $\begin{array}{l}\text { Unstable } \\
\text { The system is stabil- } \\
\text { ized with } 1332(\mathrm{MW}) \\
\text { remedial action }\end{array}$ & $\begin{array}{l}\text { Unstable } \\
\text { The system is stabil- } \\
\text { ized with } 2550(\mathrm{MW}) \\
\text { remedial action }\end{array}$ & $\begin{array}{l}\text { Stable } \\
\text { The system is stabil- } \\
\text { ized with } 0 \text { (MW) } \\
\text { remedial action }\end{array}$ & $\begin{array}{l}\text { Unstable } \\
\text { The system is stabil- } \\
\text { ized with } 2500 \text { (MW) } \\
\text { remedial action. }\end{array}$ \\
\hline Condition & Algorithms & Case 5 & Case 6 & Case 7 & Case 8 \\
\hline Off-peak load & $\begin{array}{l}\text { No action } \\
\text { The proposed SPS }\end{array}$ & $\begin{array}{l}\text { Unstable } \\
\text { The system is stabil- } \\
\text { ized with } 1350(\mathrm{MW}) \\
\text { remedial action }\end{array}$ & $\begin{array}{l}\text { Unstable } \\
\text { The system is stabil- } \\
\text { ized with } 2271 \text { (MW) } \\
\text { remedial action }\end{array}$ & $\begin{array}{l}\text { Stable } \\
\text { The system is stabil- } \\
\text { ized with } 0 \text { (MW) } \\
\text { remedial action }\end{array}$ & $\begin{array}{l}\text { Stable } \\
\text { The system is stabil- } \\
\text { ized with } 0(\mathrm{MW}) \\
\text { remedial action }\end{array}$ \\
\hline
\end{tabular}

case 3 . We can see that no remedy control action is needed in case 3 . In cases $1,2,4,5$, and 6 , the remedial control action is taken only at after second fault fails. From Table 6, it demonstrates that the proposed PMU based SPS can stabilize the unstable situations, ex. Case 1, Case 2, Case 4, Case 5, and Case 6. Also the proposed SPS will not cause a false action, ex. Case 3, Case 7, and Case 8.
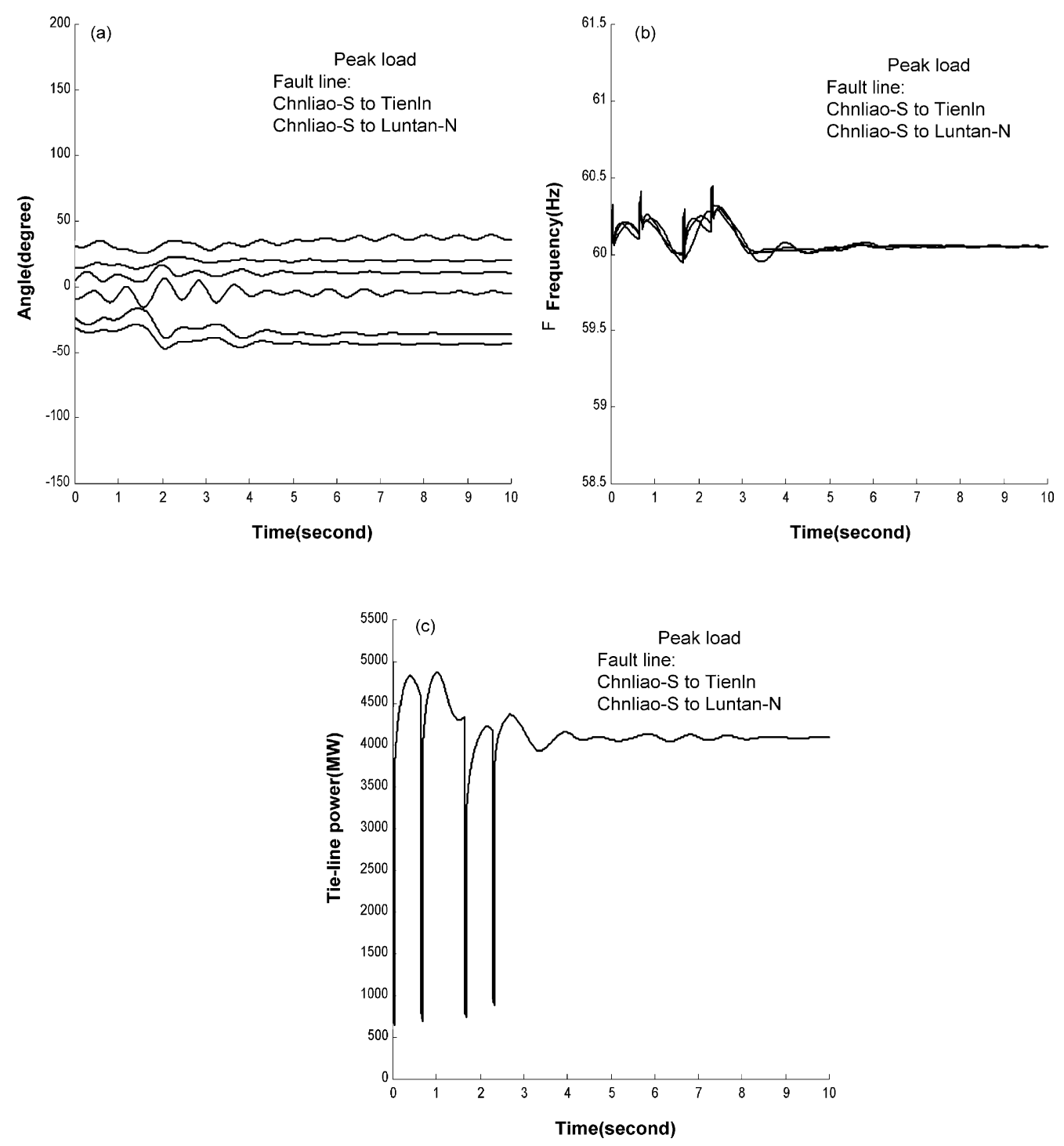

Fig. 10. Simulation results of Case 3 with PMU based SPS: (a) generator angle, (b) system frequency, (c) areas transfer power. 


\section{Conclusion}

Some power systems are stability limited (like Taipower system), and desired operating conditions may require avoiding blackout that SPS be provided in order to operate the system in a secure manner. To meet these requirements, this paper proposes PMU based SPS to prevent power system blackout due to a sequence of relay trip events. We use PMU's to monitor the generators and the major EHV transmission lines of a power system. Real-time phasor measurements are used to estimate the parameters of OMIB. The remedial control actions consist of load shedding and generation tripping. The strategy for determining the amount of remedial control actions is a proposed relay setting limited equal-area criterion for OMIB. We used global measured data to predict the system stability, and used the remedial control actions to avoid system blackout. The proposed method has been verified on Taipower system. Encouraging results are obtained.

\section{References}

[1] Department of Economic Affairs, Investigation Report of 729 event of Taiwan Power Company; September 1999 (in Chinese).

[2] Anderson PM, LeReverend BK. Industry experience with special protection schemes. IEEE Trans Power Syst 1996;11(3): 1166-79.

[3] Phadke AG, et al. Synchronized sampling and phasor measurements for relaying and control. IEEE Trans power Deliv 1994; $9(1): 442-52$.
[4] Thorp JS, Phadke AG, Horowitz SH, Begovic MM. Some applications of phasor measurements to adaptive protection. IEEE Trans Power Syst 1988;3(2):791-8.

Yi-Jen Wang was born in Taiwan in 1961. He received his BS degree in electrical engineering from National Taiwan University of Science and Technology in 1986, MS degree in electrical engineering from National Taiwan University in 1990 . He is currently working toward his $\mathrm{PhD}$ degree at National Taiwan University. His research interests include power system analysis and application of synchronized phasor measurements to enhance power system transient stability.

Chih-Wen Liu was born in Taiwan in 1964. He received the BS degree in Electrical Engineering from National Taiwan University in 1987, and $\mathrm{MS}$ and $\mathrm{PhD}$ degrees in electrical engineering from Cornell University in 1992 and 1994. Since 1994, he has been with National Taiwan University, where he is professor of electrical engineering. He is a senior member of the IEEE and serves as a reviewer for IEEE Transactions on Circuits and Systems, Part I. His main research area is in application of computer technology to power system monitoring, operation, protection and control. His other research interests include GPS time transfer and chaotic dynamics and their application to system problems.

Yuin-Hong Liu was born in Taiwan in 1959. He received the BS degree from National Cheng-Kung University in 1981, and MS degree from National Tsing-Hua University in 1983 and $\mathrm{PhD}$ degrees from the University of Texas at Arlington in 1994, all from electrical engineering. Since 1983, he has worked with the Taiwan Power Company. He is now a manager, in charge of power system operation planning. 